


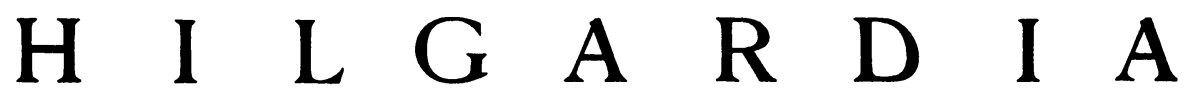 \\ A Journal of Agricultural Science Published by \\ the California Agricultural Experiment Station
}

\section{SOME PROBLEMS IN THE USE OF ARTIFICIAL LIGHT IN CROP PROTECTION ${ }^{1}$}

\author{
WILLIAM B. HERMS ${ }^{2}$
}

\section{INTRODUCTION}

WHEN THE AUTHOR first began to investigate the light reactions of blowfly larvae on the sandy beaches of Lake Erie, during the summers of 1903-1906, little did he suspect that he would be investigating the light reactions of the codling moth, Carpocapsa pomonella (Linn.), in apple orchards in California twenty-five years later. As the laboratory and field notes of the early work in Ohio are examined, two significant points that have been stressed throughout the years may be noted: (1) importance of knowing field habits, as then stated, "... behavior ... under natural conditions ... should be considered first"; this point was again stressed in 1909 (Herms, 1909); and (2) the importance of wave length and intensity. These early studies convinced the author of the powerful influence of light on the behavior of insects (and of other arthropods) (Herms, $1907 a, b$ ), and suggested the possibility of devising ways and means for the use of artificial light in the control of insects for man's benefit in crop protection (Herms and Ellsworth, 1934). In spite of many interruptions and some opposition by old-line entomologists, as well as by other interests, some progress of economic importance has been made. As an aid to future work, examination of some of the problems encountered during the course of these investigations seems appropriate.

Much of the earlier work was concerned with laboratory studies (largely unpublished) of the color reactions of various species of insects of economic importance, such as the codling moth. These investigations indicated that insects have color preferences, and that such preferences differ markedly for the various species under consideration. Furthermore, the investigations seem to justify the belief that through the use of appropriate monochromats of sufficient light intensity, certain species of harmful insects could be lured to destruction with the exclusion of harmless and beneficial forms. Experimental evidence points to the fact that certain species of insects-particularly crepuscular forms-become active on exposure to low intensities of light and, by an increase in light intensity, might be deterred from performing their egg-laying function; hence the field tests made on the codling moth.

\footnotetext{
${ }^{1}$ Received for publication January 9, 1946.

? Professor of Parasitology, Emeritus.
} 


\section{LIGHT AS A DETERRENT}

The first large-scale field tests in 1928 (Herms, 1929) were designed to test the deterrent effect of light on codling moths, as was also the second, a more elaborate test, made in the same orchard during the summer of 1929 (Herms, 1932). Under favorable conditions, codling moths deposit eggs freely within a range of light intensity from 0.3 to 90.0 foot-candles, and with maximum activity between 25 and 52 foot-candles. It therefore seemed worth while to test the efficacy of illuminating an orchard with artificial light that gave an intensity higher than optimum. In this way, it was thought the moths might be kept out of such light-protected plots and thus might be prevented from laying eggs within that area.

During the 1929 test, from April 24 to October 4, eighteen 500-watt Mazda lamps were suspended over the tops of the trees and were lighted from 2 to 4 hours daily during the sunset hours. Other factors being favorable, egg deposition takes place under natural conditions when the temperature during the sunset hours ranges from $60^{\circ}$ to $69^{\circ} \mathrm{F}$. At $55^{\circ}$ to $58^{\circ}$, egg laying usually ceases. The measure of results at the end of the tests was the percentage of wormy apples; 217,975 apples, including thinnings and windfalls, from 51 trees, were carefully examined. The worminess was 49.7 per cent in a plot wholly illuminated and unsprayed, 71.3 per cent in an unsprayed, nonilluminated plot, and 7.4 per cent in a nonilluminated, properly sprayed plot. The reduction in worminess by only about 30 per cent, through the use of highintensity light, was therefore of no great economic value. An examination of data shows an inability to maintain an adequately high degree of illumination throughout the test area (the range was from 11 to 112 foot-candles); certainly moths that entered the so-called protected plot did deposit eggs. As a matter of fact, a codling moth was seen to ovulate in a light intensity of 1,298 foot-candles. Borden (1931) records codling moths in flight at 1,928 foot-candles. Those female moths which were deterred from entering the highly illuminated area almost certainly went elsewhere to deposit their eggs. In that part of the orchard where artificial illumination kept the light intensity for the entire evening at from 0.3 to 0.4 foot-candles, there was a very high degree of worminess. To maintain a sufficiently high light intensity uniformly throughout the orchard during the critical egg-laying period appears to be exceedingly difficult and probably well beyond the margin of profit.

\section{USE OF LIGHT TRAPS}

Next studied was the possible use of light traps in codling-moth control. Some experience had already been gained (Herms, 1937) with field tests in light trapping other species, such as the Clear Lake gnat. Laboratory studies indicated a degree of attraction to certain colors; that is, when codling moths were exposed to light of several colors, but of approximately equal intensity, the response was to a pale blue with a wave length of nearly 4,350 ̊. Two problems in particular were confronted in testing the use of light traps with colored light as a lure: (1) No suitable devices were commercially available to kill the moths lured to the light. (2) Appropriate and economical monochromatic light sources were not readily available. With the aid of Dr. L. T. 
Jones, both problems were solved by the development of the needed devices: insect electrocutors and spiral gas discharge tubes which produce a large area of color (see fig. 1).

\section{LIGHT TRAPS FOR CODLING-MOTH CONTROL}

With the equipment described, the investigators went into the field during the summer of 1933 . The test period extended from May 12 to October 16, with lights on from 5 p.m. to 5 a.m. A plot of 36 apple trees was used, and at the end of the experiment a fair sampling - that is, 19,220 apples--was made for worminess. Unsprayed trees under the protection of traps with pale-blue light (with a predominant wave length of about $4,350 \AA$-found to be most attractive in laboratory experimentation) gave a worminess of 50.3 per cent. This protection was about the same as that given by intense (repellent) white flood light during 1929-49.7 per cent. Unsprayed trees under protection of traps with red light (with a predominant wave length of about $6,800 \AA$ ) showed a worminess of 77.3 per cent. Unsprayed trees under protection of traps with white light (frosted 60-watt Mazda lamp) showed a worminess of 74.2 per cent-somewhat wormier than apples from a check plot, neither sprayed nor protected by traps, showing a 73.6 per cənt worminess. Apples from trees having had only a routine arsenical spray treatment showed a worminess of 40.1 per cent (probably a defective spray program). To ascertain the number of codling moths killed by insect electrocutors at certain stations, catches were made and counted. Four traps with pale-blue light, which captured 2,930 codling moths, showed a sex ratio of 4 females to 5 males; 1 trap with 60-watt white light trapped 132 moths, with a sex ratio of 1 female to 3 males; and 1 trap with a 60-watt red light took 271 moths, with a sex ratio of 1 female to 2 males (Herms and Ellsworth, 1934). Although insect electrocutors with pale-blue light gave promising results, the use of this method as a substitute for an adequate spray program is not recommended for codling-moth control in apples.

\section{EXPERIENCE GAINED FROM FIELD TESTS}

The experience gained in this investigation has shown the complexity of any large-scale field project studying the use of light in codling-moth control. The need of thorough knowledge of the natural behavior of the insects involves the problem of employing adequate and well-trained assistants who will live day and night, over an extended period, in the native habitat of the insects. An essential problem in work of the type under consideration is, therefore, adequate financial support, which enables the employment of competent scientific assistance and the purchase of suitable equipment. Had it not been for the generous financial support of the California Committee on the Relation of Electricity to Agriculture, the field tests described in this paper, as well as many other tests, would have been impossible; this remarkable agency gave financial support to the investigation for more than ten years. Such investigations also require the generous coöperation of growers-a matter of no small importance.

Serious problems in the use of insect electrocutors in apple and pear orchards were encountered. One was the screening effect of dense foliage; the 


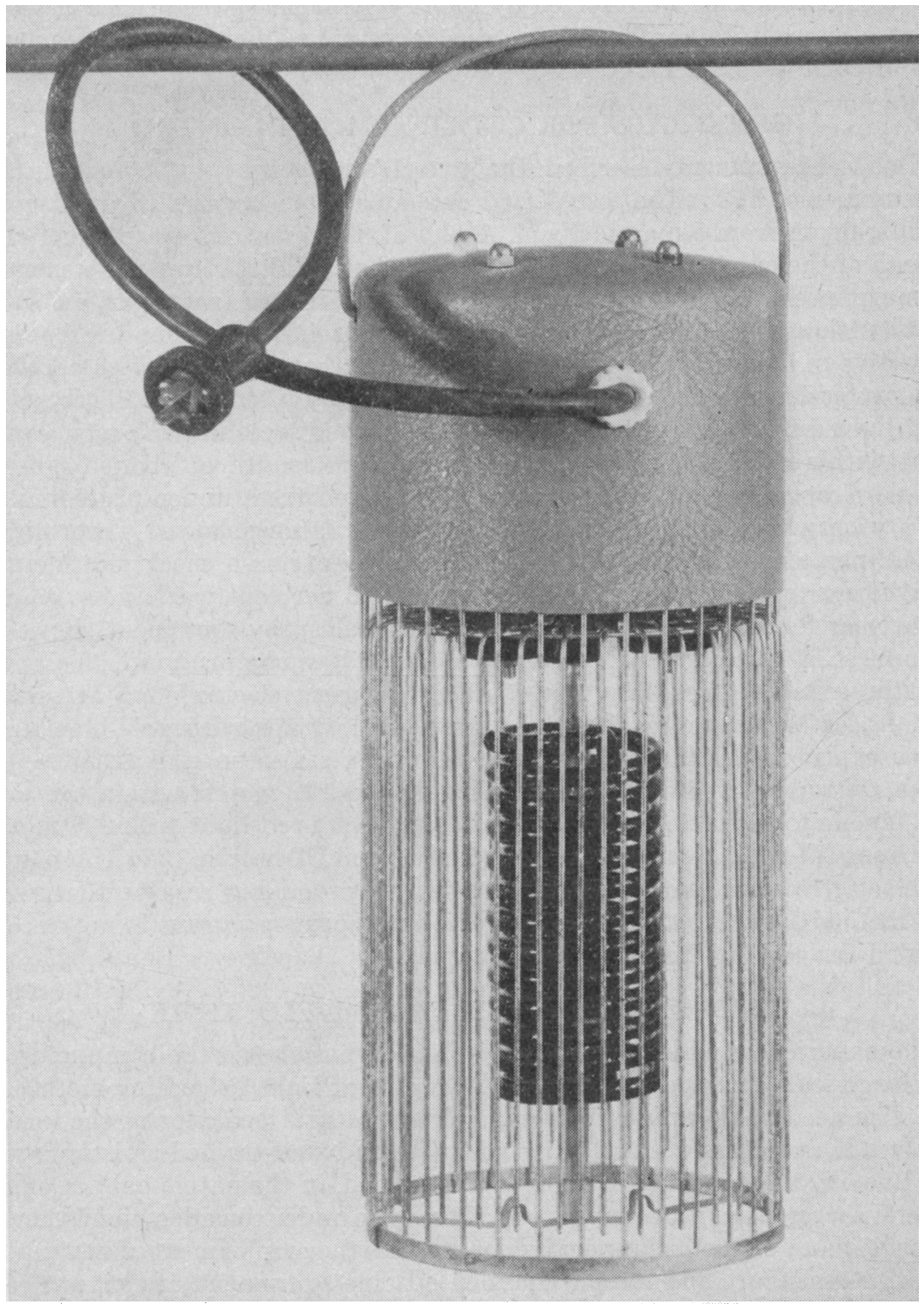

Fig. 1.-Insect electrocuting light trap used in experimental work.

height of the trees made necessary the use of poles and wiring to place the electrocutors sufficiently high. This problem led to even more elaborate field tests in vineyards, and in artichoke and tomato fields where the crop to be protected was not so tall and was more uniform. Here other problems, such as interference of wiring with cultivation and harvesting, were confronted. Throughout the investigation, safety was a factor of importance. 
In the investigation of the use of light traps in crop protection, certain public-health and economic problems constantly have been kept in mind. These are the problems arising from the use of poisonous chemical sprays and dusts which leave a residue on fruits and vegetables and have a cumulative effect on soils. That first cost and operating expenses of devices used in crop protection must be kept at a minimum, commensurate with the margin of profit, is, of course, understood. The production of such equipment is a problem in itself.

\section{LIGHT TRAPS FOR GRAPE LEAFHOPPER CONTROL}

As was done in the experiment with the codling moth, tests were made in the laboratory to determine the color preference of the grape leafhopper, Erythroneura comes (Say). At the time, this insect was causing a heavy loss to vineyardists in the major grape areas of California. The grape leafhopper is strongly positive to light, and laboratory tests indicated a marked response to clear blue (somewhat lighter than pale blue). During the course of the field tests, begun in 1934 and covering a five-year period, 17 separate installations were studied; these represented a total of 156 traps in plots located over a wide area in the San Joaquin Valley.

Tests made for relative effectiveness of (all 60 watt) (1) clear blue (a new light developed for this purpose and found by laboratory tests to give the greatest degree of response), (2) pale blue (previously found to be effective for codling moth), (3) dark blue, (4) red, and (5) white incandescent lamp, showed that the clear blue attracted greater numbers of leafhoppers in the field than any other light; the clear blue attracted more than twice as many hoppers as did the white incandescent lamp, and the dark blue attracted about the same number as the red. However, about four times as many females were taken by the trap with the dark-blue light as by the trap with the white, and ten times as many as by the trap with the red light. The sex ratio for the red light was 10 males to 1 female. Later tests indicated that the clear blue attracted not only the largest number of hoppers but also the highest percentage of females.

Population studies indicated that one insect electrocutor per acre killed a sufficient number of leafhoppers daily to afford protection. Therefore, the practice of using one trap with clear-blue light, per acre, was adopted for practical purposes. Tests made with lights (Herms and Ellsworth, 1935) of the same color, but with increased intensities, proved interesting and of practical value in that an increase in intensity from 60 watts to 150 watts increased the number of leafhoppers from 399 to 844 per trap per night-more than twice the number. Also, during a period from August 27 to October 23, 1934, a trap with a 60-watt dark-blue light took a total of 103,000 hoppers, an average of 1,758 per night, while a trap in the same general area with a 120 watt pale-blue light took a total of 264,000 , or an average of 4,551 leafhoppers per night-better than two and a half times as many. Had the investigators used the clear-blue lights, referred to earlier, for this test, undoubtedly the number of leafhoppers captured would have been increased even more.

That the proper location of traps, with reference to the vineyard as a whole, is important is indicated by the fact that vineyards in which light traps were 
used showed heavy foci of Pierce's disease of grapevines in the immediate vicinity of light traps. In fact, it was this observation that caused suspicion to rest on leafhoppers as vectors of this disease. These traps attract vast numbers of leafhoppers of many species. The grape leafhoppers are small and fly readily into the insect electrocutors; other leafhoppers (sharpshooters)

TABLE 1

Insects Taken During Two Nights (August 23 and 24, 1938) BY LIGHT IN A VINEYARD

(Traps with 60-watt pale-blue lights, at different elevations)

\begin{tabular}{|c|c|c|c|}
\hline \multirow{2}{*}{ Insects* } & \multicolumn{3}{|c|}{ Elevation } \\
\hline & $7 \mathrm{ft}$. & $12 \mathrm{ft}$. & $17 \mathrm{ft}$. \\
\hline Coleoptera, total......... & 5,698 & 5,044 & 5,089 \\
\hline 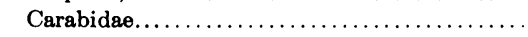 & 987 & 550 & 813 \\
\hline 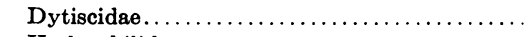 & 480 & 1,051 & 321 \\
\hline Hydrophilidae... & 136 & 226 & 210 \\
\hline Chrysomelidae..... & 1,231 & 778 & 870 \\
\hline Coccinellidae............... & 1 & 22 & 0 \\
\hline Curculionidae..... & 169 & 447 & 576 \\
\hline Hemiptera, total. . & 298 & 685 & 861 \\
\hline Miridae......... & 249 & 227 & 740 \\
\hline Lygaeidae........ & 25 & 14 & 31 \\
\hline Reduviidae...... & 2 & 28 & 15 \\
\hline Homoptera, total. & 104 & 568 & 890 \\
\hline Cicadellidae...... & 104 & 568 & 888 \\
\hline Lepidoptera, total.. & 567 & 391 & 205 \\
\hline Noctuidae ....... & 49 & 29 & 25 \\
\hline Microlepidoptera..................... & 508 & 262 & 165 \\
\hline \multirow[t]{2}{*}{ Diptera, total.. } & Collection & & \\
\hline & lost & 622 & 4,554 \\
\hline Chironomidae.................. & & 164 & 2,097 \\
\hline Sciaridae.................... & & 211 & 2,001 \\
\hline 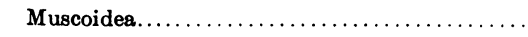 & & 179 & 224 \\
\hline Hymenoptera, total. & 12 & $s$ & $s$ \\
\hline Ichneumonidae. .......... & 5 & 2. & 0 \\
\hline Trichoptera.. & 19 & 17 & 4 \\
\hline Total, all insects. . & 6,692 & $6,448^{*}$ & $7,052 \dagger$ \\
\hline
\end{tabular}

* Totals for orders also include insects not shown by families.

$\dagger$ Exclusive of Diptera.

are heavy bodied and are freely attracted to the light, but they collect in great numbers in a rough circle below the light traps. During 1941 conclusive proof was shown that Pierce's disease was transmitted by two species of leafhoppers, namely, Draeculacephala minerva Ball and Carneocephala fulgida Nott. (Hewitt, et al., 1942). Both species feed on alfalfa and wild marsh grasses; the infection they transmit to alfalfa causes alfalfa dwarf. Although the evidence is only circumstantial, the belief exists that the lights attract the hoppers from adjacent infected alfalfa fields into the vineyards and thus cause the foci of Pierce's disease in the vicinity of the traps. If this evidence 
is true, it presents a problem of such proportions that further investigation is required. The great peril to the grape industry presented by Pierce's disease renders undesirable what otherwise might have been a practical control of the grape leafhopper in certain areas.

\section{USE OF LIGHT TRAPS AGAINST ARTICHOKE PLUME MOTHS}

Another important crop which was believed to lend itself to a study of light traps in protection against a serious pest-the plume moth-was the artichoke. Laboratory tests showed that the artichoke plume moth, Platyptilia carduidactyla (Riley) was strongly phototactic, was a night flier, and responded most favorably to a dark-blue light. Extensive field tests were conducted during the period from 1936 to 1938; although encouraging results were obtained, indications pointed to the fact that light traps, when used as a sole means of control, did not offer adequate protection. However, during the period of July, 1937, to December, 1938, further tests were made in an 8-acre field with one 60-watt dark-blue light trap used per acre. At sunset and at sunrise the traps were turned on and off automatically, unless the temperature dropped below $50^{\circ} \mathrm{F}$, under which conditions the thermostat opened the switch and the lights went off. The number of plume moths captured for the 18-month period was 2,032, an average of 3.85 moths a day for 8 traps. The sex ratio was 1 female to 5.5 males. A 60 -watt white incandescent lamp was tried but very few female moths were attracted. A general summary is given by Lange (1941) as follows :

Important factors which were found to influence the capture of moths at light traps were, first, the height of the traps, second, night temperatures, and third, the intensity of wind currents. An experiment in which light traps were placed at different heights from the ground, demonstrated that most moths were taken about the level of the artichoke plants, usually from 3 to 5 feet, with a few taken at 8 feet, but none at 12 feet. The moths were found to be capable of reaching considerable heights in the air when aided by wind currents, but were not able to direct their flight sufficiently to hit a light trap placed at 12 feet in the air. Night temperature was found to be an important factor in that often a difference of only $2^{\circ} \mathrm{F}$ determined the difference between moths flying or not flying. For purposes of light-trap operation, $50^{\circ}$ was determined as the minimum flight temperature, although flight was observed down to $46^{\circ}$. Wind currents played an important part in the capture of plume moths at light traps in that once the moths were carried beyond the traps they could not fly back. During the summer it was found that most flight begins at dusk and continues until midnight, the time depending primarily upon temperature.

\section{USE OF LIGHT TRAPS IN CORN-EARWORM CONTROL ON TOMATOES}

To test the use of light traps in the control of the corn earworm, or tomato fruitworm, Heliothis armigera (Hbn.), in tomatoes, three plots were set up for a period of about 3 months in four widely separated tomato-growing sections of California. These plots consisted of 20 acres of tomatoes with 1 trap (60-watt pale-blue light) to 2 acres; and two plots of 6 acres each with 1 trap (60-watt pale-blue light) per acre.

The number of moths taken per trap per night reached a peak about September 25 , when the average for the 60 -watt pale-blue light was 29 , with a sex ratio of 1 female to 1 male. The average per trap per night for the entire season was slightly over 3 , with a sex ratio of about 4 females to 6 males. 
Four 60 -watt light traps located in the same area and operated from July 27 to August 27 (1936) gave the following results : ${ }^{3}$

\begin{tabular}{|c|c|c|}
\hline Source of light & $\begin{array}{l}\text { Corn-earworm } \\
\text { moths }\end{array}$ & Sex ratio \\
\hline One 60 -watt pale-blue light & . .75 & 3 females to 7 males \\
\hline One 60 -watt red light & . 29 & 2.5 females to 7.5 males \\
\hline One 60 -watt white Mazda lamp & 74 & 2 females to 8 males \\
\hline One 60-watt daylight Mazda lamp & . 43 & 3.7 females to 6.3 males \\
\hline
\end{tabular}

In the artichoke investigations conducted at Moss Beach from August 1 to August 30,1936, Lange (1941) used 4 traps, each containing a 60-watt darkblue light. He captured an average of about 150 corn-earworm moths per trap per night, for the 30-day period, with a sex ratio of 1 female to 1.7 males.

\section{HEIGHT OF TRAPS}

The height of the light traps has already been mentioned. To ascertain the height at which codling moths fly, traps were placed in an apple orchard. One trap was placed about 2 feet above the tops of the trees-about 21 feet highthe other at an elevation of 35 feet. Both traps had 60 -watt pale-blue lights. During the month of July the trap placed at a height of 21 feet captured 399 codling moths (53 per cent females) and the trap placed at an elevation of 35 feet captured only 29 moths ( 51 per cent females) (see footnote 3 ).

Another test was made by placing 3 traps, each with a 60 -watt pale-blue light, over a vineyard at heights of 7 feet, 12 feet, and 17 feet, respectively. A tabulation of the catch for the 2 nights (counting only Coleoptera, Hemiptera, Homoptera, Lepidoptera, Hymenoptera, and Trichoptera, given in table 1) shows little difference in the total number of insects taken at the traps. If the Diptera, eliminated because of lost records, were included in the catch for the 17-foot elevation, this elevation would show a distinct advantage with a very large collection of Chironomidae and Sciaridae. Both the Hemiptera and Homoptera showed increased catches at increased elevation; but the Lepidoptera showed a decrease at increased elevation, particularly noticeable in the Microlepidoptera. This decrease was also very marked in the Chrysomelidae (Coleoptera).

\section{LIGHT TRAPPING OF INSECTS IN PACKING-HOUSE AND FIG DRYING YARD}

In an experiment conducted by Ellsworth (1939) (see footnote 3) at a packing-house, during the period March 29 to July 7, 1938, a total of 6,920 codling moths was electrocuted through the use of 5 insect electrocutors. The lights were rotated counterclockwise at two-week intervals to equalize any advantage in position. The results were as follows :

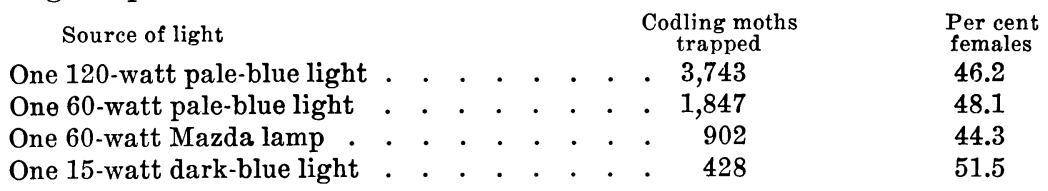

${ }^{3}$ Ellsworth, J. K. A critical and experimental study of the use of light, particularly monochromatic light, in the control of insects. Thesis for the degree of Doctor of Philosophy, University of California, 1939. (Typewritten.) Copy on file in the University of California Library, Berkeley, Calif. 
Two insect electrocutors, one with dark-blue and the other with pale-blue light, were operated for 4 successive nights (October 11 to October 15, 1933) in a fig drying yard at Fresno (California) where figs are dried on stacked trays. Moths were quite numerous in this yard. In the summarized results which follow ${ }^{4}$ apparently all of the Ephestia sp. were E. figulilella Greg. Of the 1,578 captured by the dark-blue light, 51.9 per cent were females, and of the 739 captured by the pale-blue light, 53.4 per cent were females. Many of these females were gravid.

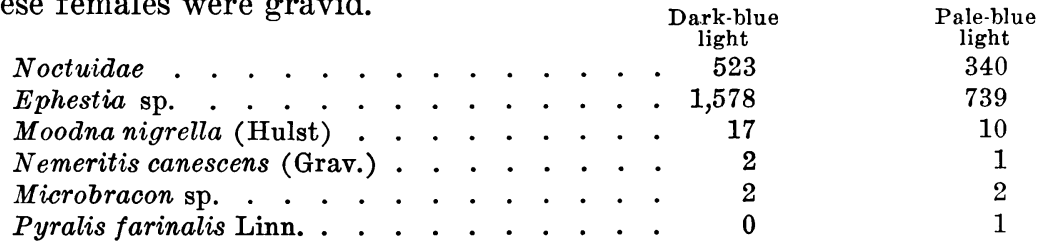

\section{CLIMATIC FACTORS THAT MILITATE AGAINST USE OF LIGHT TRAPS}

Many climatic factors militate against the use of light traps as a general means of insect control-temperature, humidity, and also wind. Lawson (1930) collected leafhoppers for species studies by using a light trap, equipped with a 200-watt Mazda bulb, suspended 8 feet above the ground. In discussing the results of collecting leafhoppers for two seasons in this manner, Lawson comments as follows :

It is perfectly clear that cold weather, severe rains, and high winds keep leafhoppers close to the ground or in their diurnal habitats. It is not so easy, however, to state the conditions under which they swarm to lights in unusual numbers... but favorable weather conditions are absolutely necessary if they are to fly to lights in large numbers.... If a large number of leafhoppers are present they will swarm to lights when there is little wind, and when there is a favorable combination of high temperature and high humidity.

The great irregularity with which leafhoppers appear at lights is shown in Lawson's table of catches for Draeculacephala mollipes (Say) and Euscelis obscurinervis (Stål.). The total catch of the former for August was 59,713 and the total catch of the latter for September was 112,998. For the former, there were only 2 nights when the catch was between 20,000 and 23,$000 ; 1$ night, 8,409; 2 nights between 1,500 and 2,000; and all other nights under 900 . In the case of $E$. obscurinervis there was a catch of 70,225 during 1 night and the next nearest catches for 2 nights were between 10,000 and about 11,000. On most other nights the catches were less than 800 ; and on several nights none was caught.

Every entomologist interested not only in light traps but also in the behavior of insects generally should read and carefully study the masterful contribution by Williams (1940). Williams points out that:

It is impossible to study insects in the field without realizing to what a large extent their activity and abundance are determined by the effect of the various climatic factors of the environment. It is, however, a big step from the realization that some of the factors have a large and some a smaller effect, to a proper analysis which will show on some scale of measurement exactly how much effect is produced in the fauna by a particular extent of change in one particular factor of the environment.

"Information furnished through the courtesy of Perez Simmons, Dried Fruit Insect Laboratory, U.S. Bureau of Entomology and Plant Quarantine. 
Williams groups the weather conditions under six headings: (1) temperature; (2) radiation (light); (3) moisture; (4) wind; (5) atmospheric pressure; and (6) thunder and lightning. He points out that temperature is probably the most important single factor in the climate of the cool temperate zone in a locality such as Rothamsted (England).

Bordon (1931), referring to the codling moth in particular, states :

[Its] flight is governed by temperature, humidity, light intensity, and air movements. Just which of these are the most important is difficult to state; however, light intensity, temperature, and air movements seem to play a very important role. In the Sebastopol district (California) which has a relatively low humidity as compared with the Watsonville district (California) a rise in temperature gives a decided drop in humidity. The appearance of the fog from the coast in the early evening very quickly drops the temperature and stops moth flight. The maximum temperature at which flight has been observed to start is $78^{\circ} \mathrm{F}$ and the minimum temperature for this district is $54^{\circ} \mathrm{F}$ at Sebastopol, while in the Watsonville district $55^{\circ} \mathrm{F}$ seems to be the average minimum. Too high temperatures in the early part of the evening have shown a decided check on moth flight during the months of June and July.

\section{THE INTENSITY FACTOR}

Numerous experiments were made (see Ellsworth citation, footnote 3, p. 364) with the grape leafhopper, Erythroneura comes (Say), to ascertain the effect of different intensities and color. As pointed out above, when the intensity was increased from a 60-watt incandescent lamp to a 150-watt lamp the number of leafhoppers per trap per night was increased from 399 (38 per cent females) to 844 (40 per cent females); and when the intensity was increased from 150 watts to 300 watts the number of leafhoppers was increased from 590 to 1,445 (49 per cent females) per trap per night. It was also pointed out that during the period from August 27 to October 23 a trap with the 60-watt dark-blue color took a total of 103,000 leafhoppers, or an average of 1,758 leafhoppers per night, while the trap with 120-watt pale-blue light took a total of 264,000 , or an average of 4,551 leafhoppers per night. A doubling of the wattage and a change in color resulted in better than a $21 / 2$ fold increase in the number of hoppers.

The following quotation from the author's bulletin on the Clear Lake gnat (Herms, 1937) is evidence that the intensity factor is important.

The next step was to determine whether the number of gnats attracted to lights was proportional to the intensity. A battery of lights (25-, 40-, 100-, 150-, 300-, 500-, 1,000-, and 1,500 -watt incandescent lamps) was set up along the shore. It was found that the number of gnats captured per second increased rapidly in lamps of from 25 to 300 watts and decreased in number when 1,000 watts was reached; this indicates a point of deterrence. There are 360 gnats in 100 milligrams or $1,650,000$ gnats in a pound. Over a 15-minute period the 300-watt lamp captured (approximately, by weight) 1,650 gnats per second. The 1,500-watt lamp attracted approximately the same number of gnats as the 200-watt lamp. Up to the point of deterrence the number of gnats attracted to a light is directly proportional to the increase in the intensity of that light. It was concluded that the number of gnats collected by any similar device depends upon the intensity of the light and the rate at which they are removed from the apparatus.

\section{THE WAVE-LENGTH FACTOR}

Bertholf (1931a) points out three fundamental questions to be considered in the reactions of a given animal to light of different wave lengths : (1) the extent of the spectrum for this animal-the wave lengths of the shortest and 
longest radiations to which it responds ; $(2)$ the relative efficiency of the different wave lengths eliciting the same response; and (3) the extent to which the animal distinguishes the different wave lengths or the number of chromas that it distinguishes. For his experimental work, Bertholf used a spectroscope (monochromator) of the constant-deviation type, with which desired wave lengths could be obtained. In a later publication, Bertholf (1931b) states that for his study of the relative efficiency of the light from certain lines of the ultraviolet spectrum he used a mercury vapor lamp, of quartz, the light from which was passed through a spectroscope (monochromator) provided with lenses and prisms of quartz. He found that when the curve representing the distribution of stimulative efficiency for the ultraviolet spectrum is joined to that for the so-called visible spectrum, as he found in his previous investigation (Bertholf, 1931a), two maximums are shown for the honeybee: one is in the yellow-green, at a wave length of $553 \mu$, which corresponds rather closely to that of man, and the other is in the ultraviolet at $365 \mu$, which is about four and one-half times as great as the former.

In reporting results of tests made on various species of insects, Gross (1913) states :

The relative stimulating efficiency of the rays of any part of the spectrum is independent of intensity, and is not the same for all animals nor for different ages of the same animal.... Periplaneta americana is responsive to blue, green and yellow, but is indifferent to red. It is positive to blue and negative to both green and red.

Gross used Nernst glowers on a 220 -volt circuit as the light source and obtained the colors by cutting down the spectrum by means of diaphragms of cardboard; the finer adjustments of intensity were accomplished by regulating the size of the diaphragms until light gave the same reading on a radiomicrometer.

To determine the color reactions of insects in the tests here reported, various cabinets and devices were used. These are described in detail by Ellsworth (see footnote 3, p. 364). Eastman Wratten filters were among the chromats used. The transmission spectra for the various filters were photographed. The intensity of the lights was measured and equalized by the use of a linear thermopile, galvanometer, and potentiometer. Evidence gained in the laboratory indicated a degree of response to color that differed (often but slightly) for the several species tested. Lack of equipment to produce monochromatic light of various wave lengths of high intensity, even in the laboratory, accounts for the extremely crude color designations used in this paper. For field use, the lack of monochromatic light of high intensity was even more of a problem. Table 2 shows numbers of insects taken in a vineyard, by electrocutors with different colors of light, during the night of August 22, 1938. Pale blue has first place; black (ultraviolet) has second; dark blue, third; yellow-green, fourth ; and red, least.

\section{SEX RATIO OF LIGHT-TRAPPED INSECTS}

Although not substantiated by a sufficient body of proof, the statement is generally made that white light should not be used in crop-protection operations against insects, because many beneficial forms are thus destroyed. Certainly white light does attract a large variety of night-flying phototactic 
insects, among them beneficial species-a matter which will be discussed later. However, one definite objection to the use of white light is that it attracts a preponderance of males and that such females as are attracted show, by ovarian examination, that a large percentage have already deposited their eggs. In considering sex ratio of insects taken at light traps, one should have a knowledge of the normal sex ratio under field conditions. Thus Turner

TABLE 2

Insects Collected in a Vineyard by Traps with Lights of Different Colors but of the Same Wattage (60), August 22, 1938

\begin{tabular}{|c|c|c|c|c|c|}
\hline \multirow{2}{*}{ Insects } & \multicolumn{5}{|c|}{ Light traps } \\
\hline & $\begin{array}{c}\text { Pale-blue } \\
\text { light }\end{array}$ & $\begin{array}{c}\text { Yellow- } \\
\text { green light }\end{array}$ & $\begin{array}{c}\text { Red } \\
\text { light }\end{array}$ & $\underset{\text { light }}{\text { Dark-blue }}$ & $\begin{array}{c}\text { Black } \\
\text { light }\end{array}$ \\
\hline Coleoptera, total. & 2,480 & 905 & 61 & 1,120 & 1,348 \\
\hline Chrysomelidae. & 117 & 7 & 0 & 21 & 19 \\
\hline Carabidae...... & 321 & 65 & 16 & 186 & 187 \\
\hline Dytiscidae.. & 359 & 25 & 3 & 301 & 429 \\
\hline Hemiptera, total. & 85 & 49 & 6 & $s 7$ & 49 \\
\hline Miridae....... & 59 & 40 & 4 & 14 & 4 \\
\hline Lygaeidae.... & 5 & 7 & 2 & 3 & 1 \\
\hline Homoptera, total. & 262 & 185 & 66 & 67 & 89 \\
\hline Cicadellidae.. & 260 & 134 & 49 & 65 & 89 \\
\hline Lepidoptera, total. & 94 & 98 & 6 & 120 & 145 \\
\hline Noctuidae....... & 14 & 2 & 0 & 4 & 15 \\
\hline Microlepidoptera. & 66 & 40 & 4 & 102 & 85 \\
\hline Diptera, total. & 515 & 213 & 61 & 299 & 1,202 \\
\hline Chironomidae. & 0 & 41 & 36 & 5 & 1,088 \\
\hline Sciaridae........ & 308 & 0 & 0 & 120 & 0 \\
\hline Culicidae.... & 98 & 33 & 13 & 29 & 21 \\
\hline Hymenoptera. & 2 & 1 & 0 & 0 & $s$ \\
\hline Neuroptera, total.. & 0 & 0 & 1 & 0 & 0 \\
\hline Chrysopidae. & 0 & 0 & 1 & 0 & 0 \\
\hline Total, all insects*. & 3,488 & 801 & 201 & 1,588 & 2,836 \\
\hline
\end{tabular}

* Totals for orders also include insects not shown by families.

(1918) states that the codling moth occurs in nature in a ratio of 5.5 (55.6 per cent) males to 4.5 (44.4 per cent) females. Since the sex ratio is subject to a variety of factors, one may reasonably assume that the ratio may differ for various localities; however, the ratio of 5 males to 4 females in the codling moth may be accepted with reservations. By using a 300-candle-power are lamp among the moths, Turner (1918) collected 1,289 codling moths; of these 44.7 per cent were males and 55.3 per cent were females, a difference which indicates that more females than males are attracted to light. However, the sex ratio of all species of moths taken by Turner in his test was 71.5 per cent males to 28.5 per cent females, 58 per cent of which were gravid. In the tests of Herms and Ellsworth (1934) 2,930 codling moths attracted to a 60-watt pale-blue light showed a sex ratio of about 4.5 males to 5.5 females, the same sex ratio that Turner showed for white light. 
Tests with the artichoke plume moth reported by Herms and Ellsworth (1934) showed that few moths were attracted to a 60 -watt incandescent lamp (white) with a sex ratio of 1 female to 8 males, while the sex ratio for 99 moths of the same species taken at a 60 -watt dark-blue light was 3 females to 2 males. Lange's test (Lange, 1941) with the same color and wattage of light gave for 2,082 moths a sex ratio of 1 female to 5.5 males. Such extreme variations in results indicate an array of problems, largely climatological.

\section{CONSERVATION OF BENEFICIAL INSECTS}

In a two-day test on August 23 to 24, 1938, made over a vineyard with 22 traps, and using lights of various colors and intensities, a total of 110,225 insects was trapped and later segregated into orders and families. Of this total, taken at various traps, only 19 were Chrysopidae and 70 beneficial Hymenoptera. Much more research needs to be done before a conclusive answer can be given as to whether or not light traps constitute a menace to beneficial insects. Surely the percentage taken under the conditions stated above is extremely small, namely, about 0.008 per cent, hardly sufficient evidence to condemn the use of properly controlled light trapping in crop protection operations (Patch, 1938). A review of the investigations of the use of light in crop protection would soon convince any unprejudiced entomologist (or conservationist) that the investigators were opposed to the indiscriminate use of light traps and that they had as their objective the discovery of a monochromatic light specific to a given pest, to the exclusion (or the saving) of other insects not involved in the damage (Herms, 1934).

\section{SAFETY FACTOR IN THE USE OF ELECTROCUTING LIGHT TRAPS}

The placing of light traps high above the ground for use against orchard insects offers little danger; but when they are used in the protection of grapes, artichokes, and tomatoes, where they require elevations nearer to the ground, the safety factor in insect electrocutors must be taken into consideration. These traps cannot be economically protected by wire basket guards. Limiting the current to make them harmless to human beings and animals seems to be the simplest way of eliminating the hazard. Tavernetti and Ellsworth (1938) pointed out two problems that had to be solved in order to obtain the safety factor: (1) the determination of the current that is safe for human beings and animals; and (2) the determination of the current and voltage necessary for the efficient operation of the device. A third point, the current necessary to kill the various species of insects, must also be determined.

Experiments were conducted by Dalziel (1938) to determine the amount of current that can be voluntarily tolerated by humans. He reported on tests with 56 men between twenty and forty years of age, in which 60 -cycle current was used. In these tests, 13.9 milliamperes was the average and 22 milliamperes the maximum tolerable current from hand to hand, and 12.6 milliamperes was the average and 18 milliamperes was the maximum current which could be tolerated, yet permit the person to release a conductor grasped by the hand. Dalziel also reported that the amount of tolerable current was dependent on the frequency but independent of the voltage. 
Tavernetti and Ellsworth (1938) used potato tuber moths and green-bottle flies to determine the electrical requirements for efficient operation of the electrocuting devices in killing insects. At least three important factors must be taken into consideration : (1) voltage between grid bars; (2) average line current; and (3) spacing of grid bars. Tavernetti and Ellsworth found that up to about 15 milliamperes' current drain, the voltage needed for electrocution decreased fairly rapidly with an increase in current. Little was gained in going above 15 milliamperes and there is a minimum voltage below which a 75 per cent kill is not possible regardless of the current. Approximately 250 to 500 volts are required for each $1 / 32$-inch spacing between grid bars to obtain a 75 per cent kill.

These authors point out that, in the practical use of electrocuting grids on insect electrocuting traps, various factors other than the killing of the insects must be considered in determining the electrical requirements : (1) The use of high voltage makes insulating more difficult and increases the corona loss (when about 5,000 volts were exceeded, the corona was both audible and visible in a dark room from the loose ends of the bars). (2) The line current can never be less than that needed for the light at proper intensity; the use of neon light (which is common where colored light is used) presents a problem in reducing the current; and, since the intensity of the light is important in attracting the insects, reduction in current reduces the intensity and thus cuts down the number of insects attracted. (3) Since the grid must be kept clear of dead insects, the grid-voltage transformer must be of sufficient size to supply enough current to burn the insects or to knock them off by arcing, when they stick on the grid.

During the summer of 1927, Herms and Burgess devised a suction-fan trap as a substitute for insect electrocutors in the control of the Clear Lake (California) gnat. The electrocuting devices quickly became clogged and inoperative until cleaned, hence the idea of a device in which there was installed a fan with a motor which sucked the insects down from the light (a 300-watt lamp) into a black muslin bag. With one of these devices (Herms and Burgess, 1928 ; and Herms, 1937), 2 pounds of gnats were trapped in 2 hours, or a total of 156 pounds during one summer. Among the difficulties encountered in the operation of these devices were: (1) clogging of the fan with gnats, a condition which required almost constant attention; and (2) many of the gnats remaining alive in the bag, which made their disposal difficult. Traps of this type are comparatively safe to operate.

\section{DISCUSSION}

Presented in this paper is a summarized account of certain experiments made with artificial light, particularly with insect electrocuting light traps under field conditions, in the control of insects. This exploratory work covers a period of more than twelve years of field operations with such crops as apples, pears, grapes, artichokes, and tomatoes. The following species of crop pests were used in the experiment: codling moth, Carpocapsa pomonella; grape leafhopper, Erythroneura comes; artichoke plume moth, Platyptilia carduidactyla; and the corn earworm or tomato fruitworm, Heliothis armigera. Laboratory experiments on a limited number of species indicate a 
possible specific color selection; and if light traps could be devised with monochromats appropriate to certain phototactic insect pests, a method of crop protection that would not destroy beneficial insects in appreciable numbers might be developed. Such a method of crop protection would avert the residues on fruits, berries, and vegetables which result from poisonous sprays and dusts. Deleterious effects on soil from accumulations of insecticidal sprays and dusts, such as arsenic, would also be avoided.

Much more refined experimental laboratory work must be done to prove conclusively the theory of color selection. Light traps for field operations must be provided with monochromats. Present available traps do not usually have light sources that produce monochromatic light of sufficient area and intensity. Much more correlative work must be done in the laboratory and in the field. Technical equipment and administrative coöperation are needed.

Experience gained in the field has impressed investigators with the complexity of any large-scale field project. A thorough knowledge of the natural behavior of the insect under all ecological conditions is essential in this type of investigation. A vast number of problems are encountered, and this paper attempts to evaluate such ones as climatological factors, position of traps, intensity of light, size of light source, and color (wave length). Each problem must be considered with adequate knowledge of the particular species under experimentation.

The measure of success in the use of artificial light, particularly the various types of light traps, in crop protection is commonly indicated by the numbers of insects destroyed. The grower is not much impressed with the numbers (though great) of insects destroyed by electrocuting light traps, for example, but he is very much interested in the degree of worminess and the grade of the fruit. While a measure of effectiveness is not indicated in terms of numbers of insects taken per trap per night, most of the reports used for Experiment Station purposes are in percentage of worminess; these reports are comparisons between plots receiving no chemical treatment and plots receiving standard applications of sprays or dusts. The percentages of worminess of apples, artichokes, and tomatoes show a fairly close inverse correlation with the numbers of particular pests destroyed by the electrocutors. With grapes, success was measured in terms of the grade of grapes harvested. With apples, in the same test plot under artificial white-light illumination during the flight period of the codling moth for two consecutive seasons, the worminess was about 50 per cent compared with a worminess of about 71 per cent in nonilluminated and nonsprayed test plots and a worminess of about 7 per cent in a nonilluminated, properly sprayed plot. Little can therefore be said in favor of using the so-called intense white light as a deterrent. The use of insect electrocuting light traps equipped with pale-blue light (about 4,350 A) resulted in holding down the worminess of apples to about the same degree as did the repellent white light, namely about 50 per cent compared with about 75 per cent worminess in an unsprayed check plot without light traps. Tests made on tomatoes and artichokes were too limited in extent to derive conclusive evidence, although the fruits of both lend themselves well to a study of worminess. Engineering problems in setting up a system of wiring for light traps in cultivated fields differ materially from those used in orchards. 
Economical as well as effective light-trap installations were used on a large scale in various parts of the San Joaquin Valley. These traps resulted in markedly higher yields and in high quality of grapes because of lessened damage by leafhoppers (Ellsworth, 1938). Unfortunately, because of the farreaching power of photic attraction, leafhoppers infected with the virus of Pierce's disease of grapevines may be drawn into a vineyard from some distant point, with serious consequences. The use of electrocuting light traps with appropriate monochromats in grape-leafhopper control gives much promise were it not for the presence of this disease of the vine. The promising results achieved in the control of the Clear Lake gnat warrant further study of this problem as well. 


\section{LITERATURE CITED}

BeRTHOLF, L. M.

1931a. Reactions of the honeybee to light. Jour. Agr. Res. 42:379-419.

1931b. The distribution of stimulative efficiency in the ultraviolet spectrum for the honeybee. Jour. Agr. Res. 43:703-13.

BORDEN, A. D.

1931. Some field observations on codling moth behavior. Jour. Econ. Ent. 24:1137-45.

DaLzIEL, C. F.

1938. Danger of electric shock. Elect. West. 80(4):30-31.

ElLswORTH, J. K.

1938. Light electrocution control of insects. Blue Anchor 15(7):14-16, 25, 26.

Gross, A. O.

1913. The reactions of arthropods to monochromatic lights of equal intensities. Jour. Exp. Zoöl. 14(4):467-514.

Herms, W. B.

1907a. An ecological and experimental study of Sarcophagidae with reference to lake beach debris. Jour. Exp. Zoöl. 4(1):45-83.

1907b. Notes on a Sandusky Bay shrimp, Palaemonetes exilipes Stimpson. Ohio Nat. $7(4): 73-79$.

1909. Recent work in insect behavior and its economic significance. Jour. Econ. Ent. $2(3): 223-30$.

1929. A field test of the effect of artificial light on the behavior of the codling moth Carpocapsa pomonella Linn. Jour. Econ. Ent. 22(1):78-88.

1932. Deterrent effect of artificial light on the codling moth. Hilgardia $7(7): 263-80$.

1937. The Clear Lake gnat. California Agr. Exp. Sta. Bul. 607:1-22.

Herms, W. B., and R. W. Burgess.

1928. Combined light and suction fan trap for insects. Elect. West. 60(14):204-06.

Herms, W. B., and J. K. Ellsworth.

1934. Field tests of the efficacy of colored light in trapping insect pests. Jour. Econ. Ent. $27(5): 1056-67$.

1935. The use of colored light in electrocuting traps for the control of the grape leafhopper. Agr. Engin. 16(5) :183-86.

HewitT, W. B., N. W. Frazier, H. E. Jacob, and J. H. Freitag.

1942. Pierce's disease of grapevines. California Agr. Exp. Sta. Cir. 353:1-32.

LANGE, W. H., JR.

1941. The artichoke plume moth and other pests injurious to the globe artichoke. California Agr. Exp. Sta. Bul. 653:1-71.

Lawson, Paul B.

1930. Another season's trap-lighting of leafhoppers. Kansas Ent. Soc. Jour. 3(2):35-43.

Patch, Edith M.

1938. Without benefit of insects. Brooklyn Ent. Soc. Bul. 38(1):1-9.

TAVERnETTi, J. R., and J. K. ElLisworth.

1938. Energy requirements and safety features of electric insect traps. Agr. Engin. $19(11): 485,486,490$.

TURNer, W. B.

1918. Female Lepidoptera at light traps. Jour. Agr. Res. 14(3):135-49.

Williams, C. B.

1940. An analysis of four years' captures of insects in a light trap. Part II. The effect of weather conditions on insect activity; and the estimation and forecasting of change in the insect population. Roy. Ent. Soc. London Trans. 90(8):227-306. 

(x) 